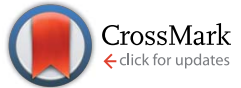

Cite this: Chem. Sci., 2017, 8, 3770

\title{
Anion $-\pi$ catalysis: bicyclic products with four contiguous stereogenic centers from otherwise elusive diastereospecific domino reactions on $\pi$-acidic surfaces $\dagger$
}

\author{
Le Liu, ${ }^{a}$ Yoann Cotelle, ${ }^{\text {ab }}$ Juliane Klehr, ${ }^{\text {bc }}$ Naomi Sakai, ${ }^{\text {T }}$ Thomas R. Ward ${ }^{\text {bc }}$ \\ and Stefan Matile*ab
}

Anion $-\pi$ interactions have been introduced recently to catalysis. The idea of stabilizing anionic intermediates and transition states on $\pi$-acidic surfaces is a new fundamental concept. By now, examples exist for asymmetric enolate, enamine, iminium and transamination chemistry, and the first anion $-\pi$ enzyme has been created. Delocalized over large aromatic planes, anion $-\pi$ interactions appear particularly attractive to stabilize extensive long-distance charge displacements during domino processes. Moving on from the formation of cyclohexane rings with five stereogenic centers in one step on a $\pi$-acidic surface, we here focus on asymmetric anion- $\pi$ catalysis of domino reactions that afford bicyclic products with quaternary stereogenic centers. Catalyst screening includes a newly synthesized, better performing anion $-\pi$ version of classical organocatalysts from cinchona alkaloids, and anion $-\pi$ enzymes. We find stereoselectivities that are clearly better than the best ones reported with conventional catalysts, culminating in unprecedented diastereospecificity. Moreover, we describe achiral salts as supramolecular chirality enhancers and report the first artificial enzyme that operates in neutral water with anion $-\pi$ interactions, i.e., interactions that are essentially new to enzymes. Evidence in support of contributions of anion $-\pi$ interactions to asymmetric catalysis include increasing diastereo- and enantioselectivity with increasing rates, i.e., asymmetric transition-state stabilization in the presence of $\pi$-acidic surfaces and inhibition with the anion selectivity sequence $\mathrm{NO}_{3}{ }^{-}>\mathrm{Br}^{-}>\mathrm{BF}_{4}{ }^{-}>\mathrm{PF}_{6}{ }^{-}$.

Received 3rd February 2017

Accepted 16th February 2017

DOI: $10.1039 / \mathrm{c} 7 \mathrm{sc} 00525 \mathrm{c}$

rsc.li/chemical-science
Contributions of anion- $\pi$ interactions ${ }^{1,2}$ to catalysis were first demonstrated explicitly in $2013 .{ }^{3}$ Since then, anion- $\pi$ catalysis has been explored with enolate, ${ }^{4,5}$ enamine, ${ }^{6}$ iminium, ${ }^{7}$ transamination $^{8}$ and oxocarbenium ${ }^{9}$ chemistry, and the first anion- $\pi$ enzyme has been created. ${ }^{5}$ The idea of stabilizing anionic intermediates and transition states on $\pi$-acidic surfaces is a new fundamental concept. Delocalized over large aromatic planes, anion $-\pi$ interactions appear particularly advantageous to stabilize extensive charge displacements over long distances. For the conventional cation- $\pi$ catalysis, this advantage is best illustrated with the stabilization of carbocations moving along the emerging rings during the cyclization of terpenes into steroids. ${ }^{10}$ In anionic tandem, domino or cascade reactions, the key intermediates in need of stabilization are not carbocations

${ }^{a}$ Department of Organic Chemistry, University of Geneva, Geneva, Switzerland. E-mail: stefan.matile@unige.ch; Web: www.unige.ch/sciences/chiorg/matile/; Tel: +4122379 6523

${ }^{b}$ National Centre of Competence in Research (NCCR) Molecular Systems Engineering, Switzerland; Web: www.nccr-mse.ch

'Department of Chemistry, University of Basel, Basel, Switzerland

$\dagger$ Electronic supplementary information (ESI) available: Detailed procedures and results for all reported experiments. See DOI: $10.1039 / \mathrm{c} 7 \mathrm{sc} 00525 \mathrm{c}$ but enolates, nitronates, and so on. The most sophisticated domino reaction catalyzed so far with anion- $\pi$ interactions is the stereoselective formation of a cyclohexane ring from achiral starting materials. ${ }^{7}$ From there, a continuing increase in sophistication of long-distance cascade charge displacements on $\pi$-acidic surfaces naturally leads to bicyclic products on the one hand and quaternary stereogenic centers on the other. For this purpose, we focused first on the addition of cyclohexanedione 1 to nitroolefin 2 (Fig. 1). In the presence of a base, they engage in a domino Michael-Henry reaction to afford bicyclo[3.2.1] octan-8-one 3, which is a bicyclic product with four chiral centers made from achiral substrates. ${ }^{11-13}$ The first step is the Michael addition of the conjugate enolate base of $\mathbf{1}$ to acceptor 2 (see transition state TS1, Fig. 1). The resulting nitronate engages in an intramolecular Henry reaction to close the second carbocycle (TS2, Fig. 1). This reaction was attractive for anion- $\pi$ catalysis because stabilization of the anionic enolate and nitronate intermediates on $\pi$-acidic surfaces was conceivable, and the diastereoselectivity reported in the literature for metal-free organocatalysts (up to 12:1) appeared improvable. ${ }^{11-13}$ One report highlights that poor $1: 3 d r$ originates from epimerization between $\mathbf{3}$ and $\mathbf{3 d}$ in the presence of 


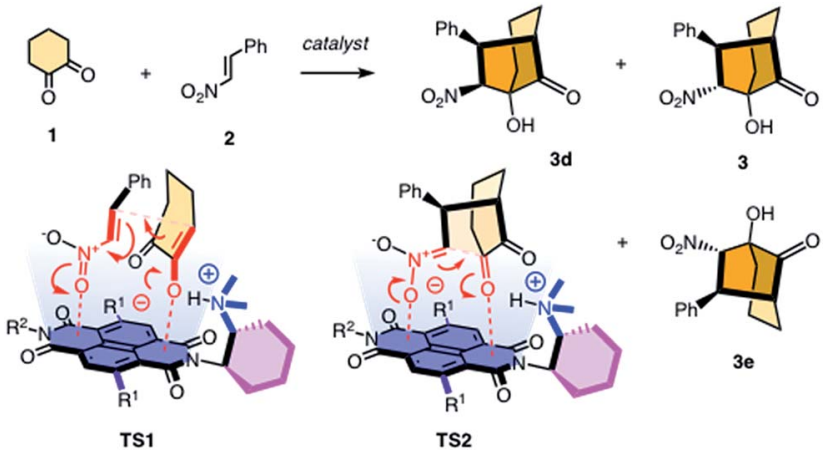

Fig. 1 The reaction selected for anion- $\pi$ catalysis of cascade reactions to bicyclic products, with notional structures for the stabilization of the anionic transition state TS1 and TS2 on the $\pi$-acidic surface of naphthalenediimides; for $R^{1}$ and $R^{2}$, see Fig. 2 .

base catalysts. ${ }^{11}$ Here, we report that domino catalysis on $\pi$ acidic surfaces provides access to diastereospecificity, i.e., the exclusive formation of one diastereomer. This breakthrough with the most sophisticated tandem process realized so far is achieved with three different functional systems, i.e., new anion- $\pi$ cinchona fusion catalysts, anion- $\pi$ enzymes and achiral anion- $\pi$ chirality enhancers. Decisive contributions from anion $-\pi$ interactions could be deduced from the observed increase in rate and stereoselectivity upon attachment of $\pi$ acidic surface, and selective inhibition with anions.

To elaborate on the formation of bicyclic products from achiral diketones on $\pi$-acidic surfaces, catalysts and controls 414 were prepared (Fig. 2). Most were accessible following reported procedures; details can be found in the ESI (Schemes S1S5 $\dagger$ ). Anion- $\pi$ catalyst 4 has been designed around the $\pi$-acidic surface of a naphthalenediimide (NDI). ${ }^{2}$ NDIs offer a privileged platform in anion- $\pi$ catalysis because their intrinsic quadrupole moment perpendicular to the $\pi$ surface is very high and can be easily modulated with substituents in the core..$^{2-8}$ In anion- $\pi$ catalyst $\mathbf{4}$, this $\pi$ surface was connected to a tertiary amine catalyst via a fixed Leonard turn. ${ }^{4}$ These turns have been introduced to assure that the reactions really occur on the $\pi$ surfaces and benefit best from anion- $\pi$ interactions, even when they are not particularly strong. ${ }^{4}$ The imide on the other side of the $\pi$-acidic surface continues with a simple solubilizing group.

In the presence of $10 \mathrm{~mol} \%$ of anion- $\pi$ catalyst, the formation of bicyclo[3.2.1]octan-8-one 3 occurred within 1-3 days at ambient temperature. The known absolute configuration of product 3e obtained with quinine $\mathbf{1 5}$ allowed us to assign the absolute configuration of enantiomer 3 obtained with 4-12 (Fig. 2d). ${ }^{12}$ Solvent screening with 4 gave best results in $\mathrm{C}_{6} \mathrm{~F}_{6}$, i.e. $10: 1 d r$ and $80 \% e e$ (Table 1, entries 12-15). With $20 \% \mathrm{C}_{6} \mathrm{D}_{6}$, a slight increase to $13: 1 d r$ coincided with a slight decrease to $77 \%$ ee (Table 1, entry 7). Further decreasing $\pi$ acidity of the solvent gradually decreased stereoselectivity down to $6: 1 d r$ and $66 \%$ ee in $\mathrm{C}_{6} \mathrm{D}_{6}$ (Table 1 , entry 4 ). These trends were interesting because they supported contributions from synergistic anion- $\pi$ interactions with polarization of the NDI plane induced by the solvent. ${ }^{14}$ From $\mathrm{C}_{6} \mathrm{~F}_{6}$, enantioselectivities could be further increased with co-solvents, best with $88 \%$ ee in $\mathrm{C}_{6} \mathrm{~F}_{6}$ / $\mathrm{CDCl}_{3} 2: 1$, but diastereoselectivity dropped to $7: 1 d r$ under these conditions (Table 1, entry 9).

In $\mathrm{C}_{6} \mathrm{~F}_{6}$, catalyst loadings could be reduced to $2.5 \mathrm{~mol} \%$ without significant losses in stereoselectivity (Table 1, entries 12-14). At $5 \mathrm{~mol} \%$ in $\mathrm{C}_{6} \mathrm{~F}_{6}$, reduction of the temperature to $5{ }^{\circ} \mathrm{C}$ further increased diastereoselectivity to $13: 1 d r$, whereas enantioselectivity did not change significantly (Table 1 , entry 15).
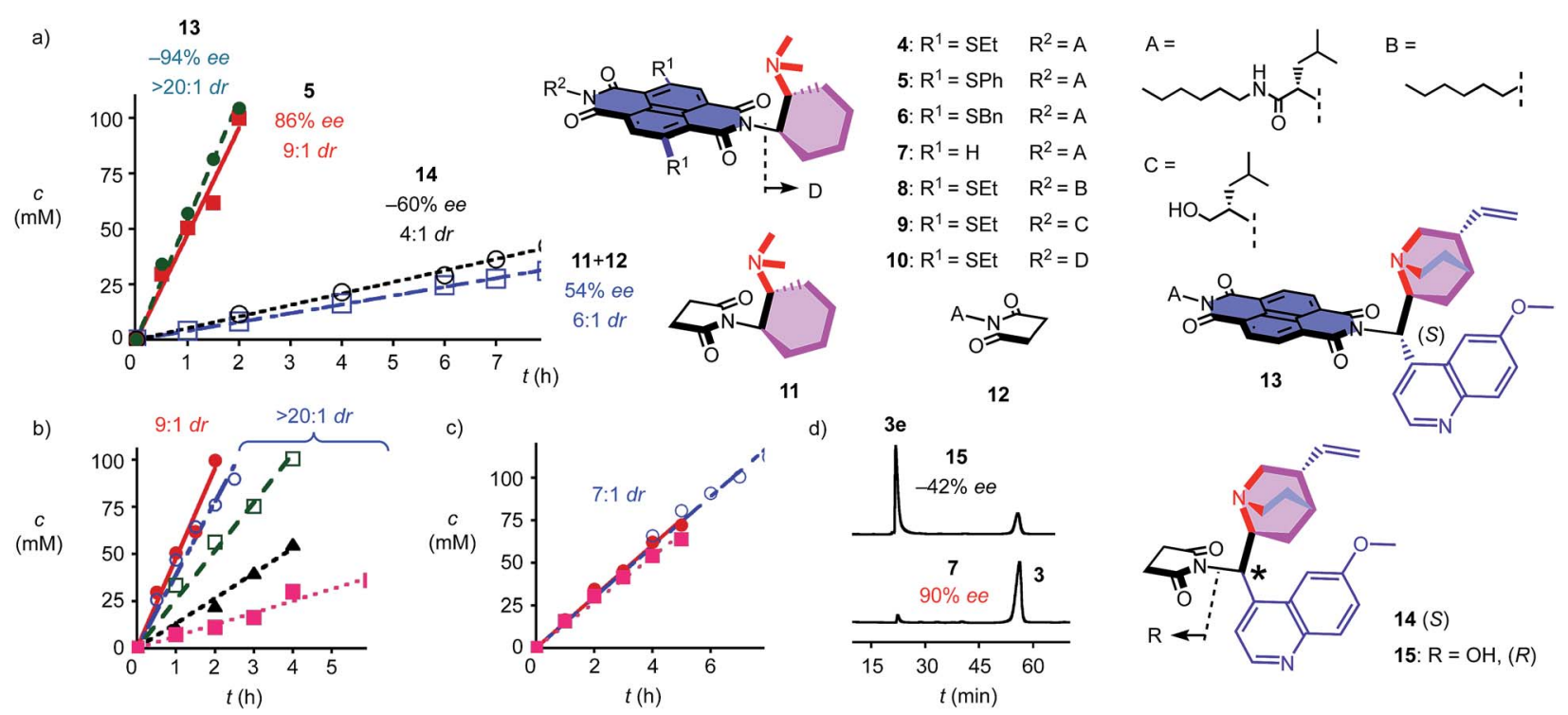

Fig. 2 Structure of original anion $-\pi$ catalysts and controls, and product concentration as a function of time (a) in the presence of catalysts 13

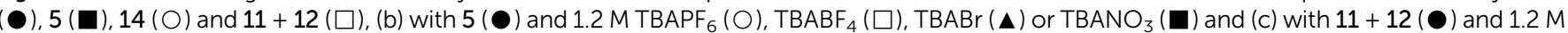
TBAPF $_{6}(\boldsymbol{\square})$ or $\mathrm{TBANO}_{3}(\mathrm{O})$. (d) Chiral HPLC analyses for product enantiomers 3e (first peak) and 3 (second) obtained with 15 (top) and 7 (bottom) 
Table 1 Catalyst performance

\begin{tabular}{|c|c|c|c|c|c|}
\hline Entry & $\begin{array}{l}\mathrm{Cat}^{a} \\
(\mathrm{~mol} \%)\end{array}$ & Conditions $^{b}$ & $\begin{array}{l}\eta^{c} \\
(\%)\end{array}$ & $\begin{array}{l}e e^{d} \\
(\%)\end{array}$ & $d r^{e}$ \\
\hline 1 & $4(10)$ & $\mathrm{CDCl}_{3}$ & 86 & 67 & $8: 1$ \\
\hline 2 & $4(10)$ & THF- $d_{8}$ & 73 & 79 & $5: 1$ \\
\hline 3 & $4(10)$ & $\mathrm{CD}_{3} \mathrm{CN}$ & 60 & 80 & $7: 1$ \\
\hline 4 & $4(10)$ & $\mathrm{C}_{6} \mathrm{D}_{6}$ & 75 & 66 & $6: 1$ \\
\hline 5 & $4(10)$ & Toluene- $d_{8}$ & 83 & 68 & $10: 1$ \\
\hline 6 & $4(10)$ & $\mathrm{C}_{6} \mathrm{H}_{5} \mathrm{NO}_{2}$ & 74 & 75 & $10: 1$ \\
\hline 7 & $4(10)$ & $\mathrm{C}_{6} \mathrm{~F}_{6} / \mathrm{C}_{6} \mathrm{D}_{6} 4: 1$ & 88 & 77 & $13: 1$ \\
\hline 8 & $4(10)$ & $\mathrm{C}_{6} \mathrm{~F}_{6} / \mathrm{CD}_{3} \mathrm{CN} 4: 1$ & 80 & 80 & $9: 1$ \\
\hline 9 & $4(5)$ & $\mathrm{C}_{6} \mathrm{~F}_{6} / \mathrm{CDCl}_{3} 2: 1$ & 92 & 88 & $7: 1$ \\
\hline 10 & $4(5)$ & $\mathrm{C}_{6} \mathrm{~F}_{6} / \mathrm{CDCl}_{3} 3: 1$ & 95 & 86 & $8: 1$ \\
\hline 11 & $4(5)$ & $\mathrm{C}_{6} \mathrm{~F}_{6} / \mathrm{CDCl}_{3} 4: 1$ & 91 & 84 & $9: 1$ \\
\hline 12 & $4(10)$ & $\mathrm{C}_{6} \mathrm{~F}_{6}$ & 93 & 80 & $10: 1$ \\
\hline 13 & $4(5)$ & $\mathrm{C}_{6} \mathrm{~F}_{6}$ & 92 & 78 & $10: 1$ \\
\hline 14 & $4(2.5)$ & $\mathrm{C}_{6} \mathrm{~F}_{6}$ & 92 & 78 & $10: 1$ \\
\hline 15 & $4(5)$ & $\mathrm{C}_{6} \mathrm{~F}_{6}, 5^{\circ} \mathrm{C}$ & 95 & 79 & $13: 1$ \\
\hline 16 & $5(5)$ & $\mathrm{C}_{6} \mathrm{~F}_{6}$ & 91 & 83 & $13: 1$ \\
\hline 17 & $6(5)$ & $\mathrm{C}_{6} \mathrm{~F}_{6}$ & 86 & 78 & $7: 1$ \\
\hline 18 & $7(5)$ & $\mathrm{C}_{6} \mathrm{~F}_{6}$ & 95 & 90 & $7: 1$ \\
\hline 19 & $9(5)$ & $\mathrm{C}_{6} \mathrm{~F}_{6}$ & 86 & 73 & $11: 1$ \\
\hline 20 & $11+12(5)$ & $\mathrm{C}_{6} \mathrm{~F}_{6}$ & 86 & 54 & $7: 1$ \\
\hline 21 & $8(5)$ & $\mathrm{C}_{6} \mathrm{~F}_{6} / \mathrm{CDCl}_{3} 2: 1$ & 94 & 89 & $9: 1$ \\
\hline 22 & $10(5)$ & $\mathrm{C}_{6} \mathrm{~F}_{6} / \mathrm{CDCl}_{3} 2: 1$ & 80 & 82 & $6: 1$ \\
\hline 23 & $13(5)$ & $\mathrm{C}_{6} \mathrm{~F}_{6} / \mathrm{CDCl}_{3} 4: 1$ & 89 & -94 & $>20: 1$ \\
\hline 24 & $14(5)$ & $\mathrm{C}_{6} \mathrm{~F}_{6} / \mathrm{CDCl}_{3} 4: 1$ & 90 & -60 & $4: 1$ \\
\hline 25 & $15(5)$ & Toluene- $d_{8}$ & 83 & -42 & $4: 1$ \\
\hline 26 & $5(5)$ & $\mathrm{C}_{6} \mathrm{~F}_{6} / \mathrm{CDCl}_{3} 4: 1$ & 91 & 86 & $9: 1$ \\
\hline 27 & $5(5)$ & $+\mathrm{PF}_{6}^{-f}$ & 90 & 90 & $>20: 1$ \\
\hline 28 & $5(5)$ & $+\mathrm{BF}_{4}^{-f}$ & 89 & 85 & $>20: 1$ \\
\hline 29 & $5(5)$ & $+\mathrm{Br}^{-f}$ & 94 & 85 & $>20: 1$ \\
\hline 30 & $5(5)$ & $+\mathrm{NO}_{3}^{-f}$ & 89 & 78 & $>20: 1$ \\
\hline 31 & $13(5)$ & $+\mathrm{NO}_{3}^{-f}$ & 92 & -94 & $>20: 1$ \\
\hline 32 & $11+12(10)$ & $\mathrm{C}_{6} \mathrm{~F}_{6} / \mathrm{CDCl}_{3} 4: 1$ & 95 & 54 & $7: 1$ \\
\hline 33 & $11+12(10)$ & $+\mathrm{PF}_{6}^{-f}$ & 94 & 30 & $10: 1$ \\
\hline 34 & $11+12(10)$ & $+\mathrm{NO}_{3}{ }^{-f}$ & 92 & 52 & $8: 1$ \\
\hline 35 & $16+\mathrm{WT}^{g}$ & Buffer pH $6.5^{h}$ & 53 & -45 & $>20: 1$ \\
\hline 36 & $16+K 121 A^{g}$ & & 39 & 0 & \\
\hline 37 & $16+\mathrm{K} 121 \mathrm{R}^{g}$ & & 47 & -20 & $>20: 1$ \\
\hline 38 & $16+\mathrm{S}_{112 \mathrm{Y}^{g}}$ & & 47 & -53 & $>20: 1$ \\
\hline 39 & $16+\mathrm{S} 112 \mathrm{~W}^{g}$ & & 51 & -76 & $>20: 1$ \\
\hline 40 & $16+\mathrm{S} 112 \mathrm{~W}^{g}$ & $+\mathrm{NO}_{3}^{-}$ & 33 & -8 & $>20: 1$ \\
\hline
\end{tabular}

${ }^{a}$ Catalysts (see Fig. 2) and loading. ${ }^{b} 1$ (entries 1-34: $0.4 \mathrm{M}$; entries $35-$ 40: $6.7 \mathrm{mM}$ ), 2 (entries 1-34: $0.8 \mathrm{M}$; entries 35-40: $16.6 \mathrm{mM}$ ), 2.5-10 mol\% catalyst, $20{ }^{\circ} \mathrm{C}$ unless stated, 1-3 days, modifications from standard conditions are indicated at first appearance. ${ }^{c}$ Yield based on crude ${ }^{1} \mathrm{H}$ NMR spectroscopy with dibromomethane as an internal standard. ${ }^{d}$ Enantiomeric excess; positive values refer to 3 , negative values to 3e, Fig. $1 .{ }^{e}$ Diastereomeric ratio, 3 vs. $3 \mathrm{~d}$ or $3 \mathrm{e} v s$. 3ed (Fig. 1). ${ }^{f} 1.2 \mathrm{M}$ TBA salts. ${ }^{g} 16$ bound to WT or mutant streptavidin as a catalyst $(5 \mathrm{~mol} \%) .{ }^{h} 33 \mathrm{mM}$ Bis-Tris, $33 \% \mathrm{MeCN}$.

Variation of the core substituents did not affect the activity of catalysts 4-7 significantly, also because the $\pi$ acidity of the $\pi$ surface was not much changed (Table 1 , entries 13 and 16-18). ${ }^{15}$ The best activity was obtained for 5 with phenylsulfides in the core, i.e., 83\% ee and $13: 1 d r$ for 5 mol\% in $\mathrm{C}_{6} \mathrm{~F}_{6}$ (Table 1, entry 16). The $90 \%$ ee obtained at maximal $\pi$ acidity without core substituents in 7 was accompanied by a decrease in diastereoselectivity to 7 : $1 d r$ (Table 1, entry 18). Similarly insignificant were variations of the second imide substituent, i.e. $R^{2}$ opposite to the Leonard-turned amine in catalysts 8-10 (Table 1, entries
19, 21 and 22). This trend suggested that these anion- $\pi$ catalysts are formally bifunctional, but not trifunctional (Fig. 1).

Cinchona alkaloids are most popular in amine-based asymmetric organocatalysis. ${ }^{\mathbf{1 1 , 1 2 , 1 6}}$ In the newly designed catalyst 13, this bicyclic amine was attached to a $\pi$-acidic surface via a Leonard turn, similar to the one introduced in catalysts 4-10 (Fig. 2). The synthesis of the new anion- $\pi$ cinchona fusion catalyst 13 was very straightforward (Scheme $\mathrm{S} 4 \dagger$ ). In $\mathrm{C}_{6} \mathrm{~F}_{6}$ / $\mathrm{CDCl}_{3} 4: 1,5 \mathrm{~mol} \%$ of cinchona catalyst 13 produced bicycle $3 \mathbf{e}$ in $89 \%$ yield with $-94 \%$ ee and only one detectable diastereomer, i.e., >20: $1 d r$ (Table 1 , entry 23). This shift from diastereoselectivity to diastereospecificity is unprecedented for this domino process; previous records in the literature, achieved with cinchona catalysts interfaced with conventional thioureas, stopped at $12: 1 d r .^{12}$ The diastereospecificity obtained with cinchona catalyst 13 suggested that on $\pi$-acidic surfaces, either the epimerization between $\mathbf{3 e}$ and $\mathbf{3 e d}$ is suppressed or the protonation of the nitronate intermediate is stereospecific.

Cinchona controls $\mathbf{1 4}$ and $\mathbf{1 5}$ without a $\pi$-acidic surface gave only $-60 \%$ ee $(4: 1 \mathrm{dr})$ and $-42 \%$ ee (lit. $-17 \% e e,^{12}$ Table 1 , entries 24 and 25), respectively. The increase in stereoselectivity upon interfacing of cinchona alkaloids with a $\pi$-acidic surface in cinchona catalyst $\mathbf{1 3}$ coincided with a rate enhancement of $v$ / $v_{0}=10$ (Fig. 2a). This acceleration corresponded to a transitionstate stabilization (or ground-state destabilization) of $\Delta E_{\mathrm{a}}=$ $-5.7 \mathrm{~kJ} \mathrm{~mol}^{-1}$. For comparison with Leonard catalyst $\mathbf{5}$, controls 11 and 12 without $\pi$-acidic surface also gave much poorer stereoselectivity (54\% ee, $7: 1 d r$ ) at a slower rate (Fig. 2a, Table 1 , entries 16 and 20). The rate enhancement $v / v_{0}=12$ corresponded to $\Delta E_{\mathrm{a}}=-6.1 \mathrm{~kJ} \mathrm{~mol}^{-1}$. The similar transition-state stabilization obtained with the conventional Leonard catalyst 5 and new fusion catalyst $\mathbf{1 3}$ was meaningful considering the similarity of the $\pi$ acidity of the respective $\pi$ surfaces. Rate enhancements coinciding with increased stereoselectivity in the presence of $\pi$-acidic surfaces provided strong support for contributions of anion- $\pi$ interactions to asymmetric catalysis. $^{3-8}$

Corroborative support for this important conclusion was obtained by inhibition with inorganic anions. Consistent with competitive anion- $\pi$ interactions, the velocity of Leonard catalyst 5 decreased in the presence of various tetrabutylammonium (TBA) salts with a selectivity sequence $\mathrm{PF}_{6}{ }^{-}<\mathrm{BF}_{4}{ }^{-}$ $<\mathrm{Br}^{-}<\mathrm{NO}_{3}{ }^{-}$(Fig. 2b; Table 1, entries 27-30). A half maximal inhibitory concentration $\left(\mathrm{IC}_{50}\right)$ of nitrate was calculated to be $0.70 \mathrm{M}$ for catalyst 5 (Fig. S17 $\dagger$ ). For cinchona catalyst 13, a similar $\mathrm{IC}_{50}=0.75 \mathrm{M}$ was obtained (Fig. S18 $\dagger$; Table 1, entry 31). Controls 11 and $\mathbf{1 2}$ were insensitive to the presence of anions (Fig. 2c, Table 1, entries 32-34). Interestingly, the diastereoselective Leonard catalyst 5 became diastereospecific in the presence of various TBA salts (Table 1, entries 26-30). The independence of this trend on the anion involved suggested that the TBA cations are responsible. A plausible explanation for this finding was that TBA cations induce the polarization of the $\pi$-acidic NDI core, comparable to the expected function of $\mathrm{C}_{6} \mathrm{~F}_{6} \cdot{ }^{14}$ Indeed, the observed acceleration of reactions with low concentrations of $\mathrm{TBANO}_{3}$ salts was consistent with this explanation (Fig. S16†). With cinchona catalyst 13 already 
producing bicycle $3 \mathbf{e}$ diastereospecifically, the discovery of achiral salts as unprecedented supramolecular anion- $\pi$ chirality enhancers for Leonard catalyst 5 suggested that both enantiomers 3 and $3 \mathbf{e}$ could be obtained diastereospecifically on $\pi$-acidic surfaces.

To position anion- $\pi$ catalysts within the chiral space of proteins, anion- $\pi$ catalyst 4 has been coupled with a biotin. ${ }^{5}$ Binding of the resulting conjugate $\mathbf{1 6}$ to streptavidin then afforded an artificial anion- $\pi$ enzyme, which operates with an essentially unknown interaction to biological enzymes (Fig. 3a). ${ }^{5}$ Interfacing of anion- $\pi$ catalysts with proteins is attractive because access to mutant screening allows performance to be readily optimized. This screening approach has previously afforded anion- $\pi$ enzymes that catalyze, at $\mathrm{pH} 3.0$, the addition of malonic acid half thioesters to enolate acceptors with 95\% ee and unprecedented chemospecificity with regard to the intrinsically favored decarboxylation. ${ }^{5}$ A focused mutant screening for the domino reaction to bicycle 3 in the presence of 16 gave best results for S112W at pH $6.5(-76 \%$ ee, Table 1 , entry 39). Mutant S112Y, the best for the addition of malonic acid half thioesters, was with $-53 \%$ ee slightly better than the wild-type (WT) protein with $-45 \%$ ee (Table 1, entries 35 and 38). K121 was confirmed as essential, presumably to keep the tertiary amine base in $\mathbf{1 6}$ from protonation under experimental conditions (Table 1, entries 36 and 37). In the presence of nitrate, the enantioselectivity decreased, with $\mathrm{IC}_{50}=0.34 \mathrm{M}$ (Fig. $3 \mathrm{~b}$, Table 1, entry 40). This finding provided experimental support for operational anion $-\pi$ interactions, i.e. the existence of anion $-\pi$ enzymes. Interestingly, all anion- $\pi$ enzymes obtained with 16 gave enantiomer $3 \mathbf{e}$ with a maximum $e e$ of $-76 \%$ as the main product in nearly neutral water/MeCN $2: 1$, whereas the protein-free analog 4 gave the opposite enantiomer 3 with a maximum $e e$ of $88 \%$ as the main product in $\mathrm{C}_{6} \mathrm{~F}_{6} / \mathrm{CDCl}_{3} 4: 1$. It is perhaps this inversion of the intrinsic enantioselectivity induced by the fixed Leonard turn derived from $1 R, 2 R$-diaminocyclohexane in both $\mathbf{4}$ and 16 that hindered access to higher $e e$ 's with anion- $\pi$ enzymes.

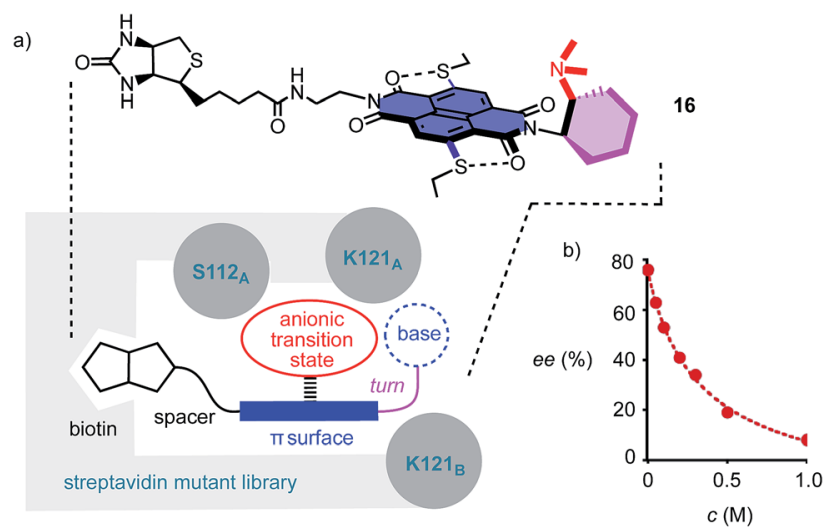

Fig. 3 a) The concept of anion- $\pi$ enzymes, with indication of the structure of the anion $-\pi$ biotin conjugate 16 interface used with streptavidin mutants and the position of the mutated key residues from monomers $\mathrm{A}$ and $\mathrm{B}$ of the streptavidin tetramer, and (b) the dependence of the ee of $3 e$ produced by the $\mathrm{S} 112 \mathrm{~W}$ mutant on the concentration of $\mathrm{NO}_{3}^{-}\left(\mathrm{NaNO}_{3}\right)$.
In summary, this study drives the development of anion- $\pi$ catalysts to unprecedented sophistication with regard to anionic domino reactions that take place on $\pi$-acidic surfaces. The most important findings are anion $-\pi$ cinchona fusion catalysts that clearly exceed the performance of conventional metal-free organocatalysts for the first time, the first example for diastereospecificity, anion- $\pi$ enzymes that operate in neutral water and the discovery of achiral tetraalkylammonium salts as supramolecular chirality enhancers. The discovery of the best anion $-\pi$ catalysts with the most sophisticated domino reaction supports the important expectation that anion- $\pi$ interactions, delocalized over large aromatic planes, will be most advantageous in stabilizing extensive long-distance charge displacements during multiple coupled anionic intermediates and transition states. Long-term perspectives include the discovery of otherwise inaccessible reactions with anion- $\pi$ catalysis, the integration into more complex systems, ${ }^{5,17}$ and the introduction of other unorthodox interactions to catalysis.,

\section{Acknowledgements}

We thank the NMR and the Mass Spectrometry platforms for services, and the University of Geneva, the Swiss National Centre of Competence in Research (NCCR) Molecular Systems Engineering, the NCCR Chemical Biology and the Swiss NSF for financial support.

\section{Notes and references}

1 (a) A. Frontera, P. Gamez, M. Mascal, T. J. Mooibroek and J. Reedijk, Angew. Chem., Int. Ed., 2011, 50, 9564-9583; (b) M. Giese, M. Albrecht and K. Rissanen, Chem. Commun., 2016, 52, 1778-1795; (c) H. T. Chifotides and K. R. Dunbar, Acc. Chem. Res., 2013, 46, 894-906; (d) D.-X. Wang and M.-X. Wang, Chimia, 2011, 65, 939-943; (e) P. Ballester, Acc. Chem. Res., 2013, 46, 874-884; (f) Q. He, Y.-F. Ao, Z.-T. Huang and D.-X. Wang, Angew. Chem., Int. Ed., 2015, 54, 11785-11790.

2 (a) M. Al Kobaisi, S. V. Bhosale, K. Latham, A. M. Raynor and S. V. Bhosale, Chem. Rev., 2016, 116, 11685-11796; (b) J.-Z. Liao, C. Wu, X.-Y. Wu, S.-Q. Deng and C.-Z. Lu, Chem. Commun., 2016, 52, 7394-7397; (c) J.-J. Liu, Y.-F. Guan, C. Jiao, M.-J. Lin, C.-C. Huang and W.-X. Dai, Dalton Trans., 2015, 44, 5957-5960; (d) S. Kumar, M. R. Ajayakumar, G. Hundal and P. Mukhopadhyay, J. Am. Chem. Soc., 2014, 136, 12004-12010; (e) S. T. Schneebeli, M. Frasconi, Z. Liu, Y. Wu, D. M. Gardner, N. L. Strutt, C. Cheng, R. Carmieli, M. R. Wasielewski and J. F. Stoddart, Angew. Chem., Int. Ed., 2013, 52, 13100-13104.

3 Y. Zhao, Y. Domoto, E. Orentas, C. Beuchat, D. Emery, J. Mareda, N. Sakai and S. Matile, Angew. Chem., Int. Ed., 2013, 52, 9940-9943.

4 Y. Cotelle, S. Benz, A.-J. Avestro, T. R. Ward, N. Sakai and S. Matile, Angew. Chem., Int. Ed., 2016, 55, 4275-4279.

5 Y. Cotelle, V. Lebrun, N. Sakai, T. R. Ward and S. Matile, ACS Cent. Sci., 2016, 2, 388-393. 
6 (a) Y. Zhao, Y. Cotelle, A.-J. Avestro, N. Sakai and S. Matile, J. Am. Chem. Soc., 2015, 137, 11582-11585; (b) K. S. Lee and J. R. Parquette, Chem. Commun., 2015, 51, 15653-15656.

7 L. Liu, Y. Cotelle, A.-J. Avestro, N. Sakai and S. Matile, J. Am. Chem. Soc., 2016, 138, 7876-7879.

8 L. Liu and S. Matile, Supramol. Chem., 2017, DOI: 10.1080/ 10610278.2016 .1258118$.

9 A. Berkessel, S. Das, D. Pekel and J.-M. Neudörfl, Angew. Chem., Int. Ed., 2014, 53, 11660-11664.

10 (a) C. R. Kennedy, S. Lin and E. N. Jacobsen, Angew. Chem., Int. Ed., 2016, 55, 12596-12624; (b) Y. Zhao, Y. Cotelle, N. Sakai and S. Matile, J. Am. Chem. Soc., 2016, 138, 42704277; (c) T. M. Bräuer, Q. Zhang and K. Tiefenbacher, Angew. Chem., Int. Ed., 2016, 55, 7698-7701.

11 M. Rueping, A. Kuenkel and R. Fröhlich, Chem.-Eur. J., 2010, 16, 4173-4176.

12 D. Ding, C.-G. Zhao, Q. Guo and H. Arman, Tetrahedron, 2010, 66, 4423-4427.
13 F. Felluga, C. Forzato, P. Nitti, G. Pitacco, E. Valentin and E. Zangrando, J. Heterocyclic. Chem., 2010, 47, 664-670.

14 (a) A. Frontera, D. Quiñonero and P. M. Deyà, Wiley Interdiscip. Rev.: Comput. Mol. Sci., 2011, 1, 440-459; (b) A. Lattanzi, C. De Fusco, A. Russo, A. Poater and L. Cavallo, Chem. Commun., 2012, 48, 1650-1652.

15 F. N. Miros and S. Matile, ChemistryOpen, 2016, 5, 219-226. 16 (a) C. M. R. Volla, I. Atodiresei and M. Rueping, Chem. Rev., 2014, 114, 2390-2431; (b) A. Moyano and R. Rios, Chem. Rev., 2011, 111, 4703-4832; (c) D. Enders, C. Grondal and M. R. M. Hüttl, Angew. Chem., Int. Ed., 2007, 46, 1570-1581. 17 (a) B. Baumeister, N. Sakai and S. Matile, Org. Lett., 2001, 3, 4229-4232; (b) N. Sakai and S. Matile, J. Am. Chem. Soc., 2011, 133, 18542-18545; (c) B. A. F. Le Bailly, L. Byrne and J. Clayden, Angew. Chem., Int. Ed., 2016, 55, 2312-2316.

18 (a) S. Benz, J. López-Andarias, J. Mareda, N. Sakai and S. Matile, Angew. Chem., Int. Ed., 2017, 56, 812-815; (b) D. Bulfield and S. M. Huber, Chem.-Eur. J., 2016, 22, 14434-14450. 